\title{
Curricular Design Based in Bodies of Knowledge: Engineering Education for the Innovation and the Industry
}

\author{
Pablo -Alejandro Quezada-Sarmiento, Liliana-Elvira Enciso-Quispe
}

Juan Garbajosa
Hironori Washizaki

\begin{abstract}
Bodies of Knowledge (BOK), contain the relevant knowledge for a disciplines as example Software Engineering (SE), System Information (SI), Information Technology (IT), Computer Science (CS), Medicine, Economics, and others areas of knowledge. BOK describes relevant knowledge for a discipline, and will need show the consensus in the Knowledge Areas (KA), and related disciplines. The development of this consensus is a prerequisite to the adoption of coherent skills development in the education context, and continuing professional programs both in public and private organizations.

In this context a systematic mapping study (SMS), it was performed to evaluate quantity and types of primary studies in an area of interest. SMS will be used as the research method within this research. The research method proposed will allow to sort and classify the information referent to the topics of this research.

This paper is an attempt to analyze existing proposals on BOK contents, structure, and make a proposal what the kind of contents it should have, and how it should be structured so that this consensus among all parties can be described and best achieved. In the same way the relevance, and useful of the BOK in the curricular design for the innovation, and the industry context is present.
\end{abstract}

Keywords-Area; Body of Knowledge; BOK; Breakdown; Component; Curricular; Design; Guide; Industry; Engineer; Software; Structure; Software Engineering Body of Knowledge; SWEBOK

\section{INTRODUCTION}

A BOK is a term used to represent the complete set of concepts, terms, and activities that make up a professional Domain. It encompasses the core teachings, skills, and research in a field or industry [38].
One of the main concerns of the software industry is to develop the talent of its human resources, since the quality, and innovation of its products and services depend to a great extent on the knowledge, the ability and the talent of software engineers [1]

Nowadays, it does not existing a consensus for the development of $\mathrm{BOK}$ about the structure and contents that it should have in order to design curriculum; for this reason this paper has reviewed existing literature to identify existing guidelines, and recommendations on the structure and contents in the context of engineering. In the same way guidelines to define the structure, and contents of BOK in the area of Engineering is proposed to design a curriculum consider the innovation and industry context. The main future work based in this research will be applied in educational context.

This paper has been structured as follows: Section I, contains the Introduction, section II introduces a Related Works, section III describes the Research Methodology used; the most relevant Findings are presented in Section IV. Then Section V introduces a conclusions, the last section the acknowledges, and references that support this paper are presented.

\section{RELATED WORKS}

Some related works to find a formal process in program specification of Curricular Design based on BOK are shown: In [31], use a process based upon the IEEE-CS/ACM CE Body of Knowledge Recommendations found in the report "Computer Engineering 2005 Curriculum Guidelines for Undergraduate Degree Programs in Computer Engineering. 
In [32], use SWEBOK to discuss Accreditation requirements, and several likely candidates for accreditation are identified among the programs surveyed for five undergraduate degree programs from Australia, the United States, and the United Kingdom.

In [33], suggests specific areas of business competencies that should be integrated into the software engineering curriculum; other suggestion was showed.

In [34], where SE2004 is the result of a multiyear effort to create curriculum recommendations for software engineering, hoping that its efforts will lead over time to a workforce more capable of tackling large and complex software projects with better productivity and higher resulting quality.

In [35], is proposed a method called: Reuse and Progress Driven Software Engineering Educational Method (RaPSEEM), it aids in organizing the software engineering body of knowledge when designing specific software engineering programs.

In [36], use BOK to develop a curriculum in eco-design, where is suggested that the curriculum structure can be categorized into levels.

\section{RESEARCH METHODOLOGY}

In order to support this paper, Systematic Mapping Study (SMS) as research method it was used. According to [23], mapping studies (MS), use the same basic methodology as SLRs but aim to identify and classify all research related to a broad engineering topic rather than answering questions about the relative merits of competing technologies that conventional SLRs address. MS reviews a broader software engineering topic and classifies the primary research papers in that specific domain. The domains of this paper is BOK.

In [16], the Mapping Study Procedures (MSP) show five stages: 1. Definition of research questions; 2. Conducting the search for primary studies; 3 . Screening papers based on inclusion/exclusion criteria; 4 . Classifying the papers; 5. Data extraction and aggregation. In the Fig. 1 the MSP stages is showed.

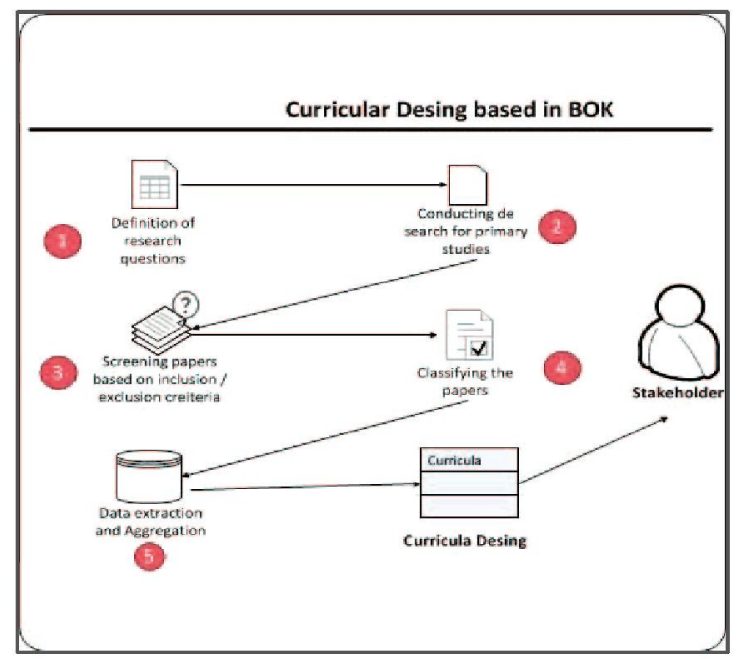

Fig. 1. The MSP stages
In this section, the research methodology followed in this research, driven by a systematic mapping and the including the data gathering technique, and the data analysis method is shown. In order to cope with this goal, SMS has been conducted to explore the existing studies relevant to BOK guidelines and recommendations that could be applied to define a BOK in the area of engineering education.

SMS are performed to evaluate quantity and types of primary studies in an area of interest in an unbiased and systematic manner. Proper procedure of executing SMS required sound planning [17].

Evidence in software engineering is getting much attention. SMS is a technique in Evidence Based Software Engineering and has already been used in different subdomains of software engineering i.e. software testing and requirement specification [18], [19].

Systematic Mapping Requires (SMR), sound planning, execution and analysis of systematic map. Data extraction conducts with the identification of categorization by screening (Title, Keywords and Abstracts) [20].

\section{SYSTEMATIC MAPPING PROCESS (SMP).}

A SMS provides a structure of the type of research reports, and results that have been published by categorizing them.

\section{Search Strategy.}

In order to develop the search strategy, it was necessary consider the title, abstract and keywords of the articles in the included electronic databases and conference proceedings will be searched according to the following search strategy [20].

1) Keywords: Body of Knowledge, BOK, Area Breakdown, Component, Curricular Design, Guide, Engineer, Software, Structure, software engineering body of knowledge, SWEBOK.

2) Alternate Spellings and Acronyms for Major Terms: SE, BOK; SWEBOK, Structure.

3) Search String: Following general search string is formed: (("BOK" OR "Body of Knowledge)") AND (("SE" OR "Software Engineering") AND ("Area Breakdown" OR "software engineering body of knowledge" OR "importance of SWEBOK." OR "Component", "OR" Curriculum, "OR" Design)).

The reason for formulating a generic string is that in mapping study we want to cover all literature in which BOK work is reported [20].

\section{Search Sources.}

To conduct the SMS, it was necessary to use a formal search strategy. Besides, to follow a formal search strategy enables recommendable practices in research contexts like the repeatability and the external reviews of this contribution [20].

In [21], to search many different electronic sources; no single source finds all the primary studies.. In an attempt to perform an exhaustive search we identified five electronic sources of relevance to Software Engineers. 
TABLE I. ElECTRONIC DATABASES CONSULTED

\begin{tabular}{|l|l|l|}
\hline \multicolumn{2}{|l|}{ Electronic databases } & Link \\
\hline Id & Data Base & www.ieeexplore.ieee.org \\
\hline 1 & IEEE Xplore Digital Library & www.dl.acm.org \\
2 & ACM Digital Library & www.webofknowledge.com \\
3 & ISI Web of Knowledge & www.sciencedirect.com \\
4 & Science Direct & www.springer.com \\
5 & Springer & \\
\hline
\end{tabular}

Inclusion and Exclusion Criteria.

Study selection criteria are intended to identify those primary studies that provide direct evidence about the research question. In order to reduce the likelihood of bias, selection criteria should be decided during the protocol definition, although they may be refined during the search process [17], [197.

Inclusion criteria. - Scientific material (papers, experience reports, summaries of workshops, etc.) written in English and accessible digitally. In the same context was necessary consider the studies framed in contexts of other discipline but vincula with concept of $\mathrm{BOK}$, workshops and meets of IEEE and $\mathrm{ACM}$.

Exclusion criteria. - Non-scientist, material none written in English. The next step is to apply inclusion and exclusion criteria based on practical issues $\underline{[25]}$ such as: Language, journal, authors, setting, participants or subjects, research design, sampling method and date of publication. In the figure 2 the criteria to evaluate papers are showed.

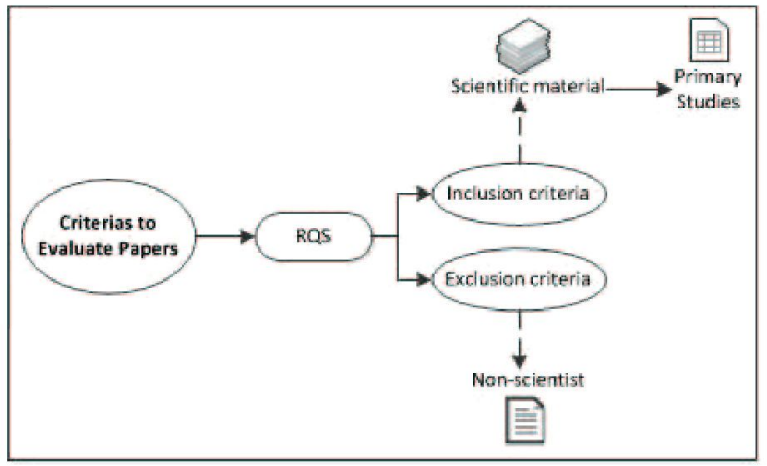

Fig. 2. Criterias to Evaluate Papers

\section{Data extraction and data synthesis strategies.}

The objective of this stage is to design data extraction forms to accurately record the information researchers obtain from the primary studies [17]. A key part of SMS is data extraction, in which essential text and data from the primary studies are obtained in an explicit and consistent way according to a defined extraction strategy. However, before starting the extraction, is recommend reading the entire set of selected papers at least once to get immersed with the data [23].

Such immersion is important in order to be familiar with the depth and breadth of the evidence. Initial ideas, and identification of possible patterns in the data will be shaped during this first reading. Although it is tempting to skip this step, most of the literature on thematic analysis advises strongly against skipping this immersion [25].

Reference [16], [17], [22] suggests:

- Publication details (e.g., authors, year, title, source, abstract, aims).

- Context descriptions (e.g., subjects, technologies, industry, settings).

- Findings (e.g., results, behaviors, actions, phenomena, events, quotes).

According to [19], in a SMS is critical to identify, to extract, and to synthesize correctly the information of the included studies to provide reliable answers to the arisen research questions.

\section{Data synthesis}

Once the data of the whole studies have been properly extracted, they should be synthesized in order to provide new knowledge in research areas in this case in $\mathrm{BOK}$, and software engineering contexts. The data extraction forms must be designed to collect all the information needed to address the review questions and the study quality criteria [17].

In the same context if the information is available from studies in progress, it should be included providing appropriate quality information about the study can be obtained and written permission is available from the researchers. [17].

In order to develop a data synthesis, it was necessary consider the Id of each primary study, the name of the authors, the year of publication, the research criteria used in each data base described in the tablel, the findings according to each RQS, and the score according the quality criteria to evaluate the primary studies.

\section{Systematic Mapping Execution (SME):}

In order to apply the SME it was necessary considering the context of each research question, and relationship with the goal of our research. In the same context the template has been created to keep (i) the context of a study, (ii) the findings related with our research questions, and (iii) the reliability and suitability of the study for our purposes.

The searching process has been executed following the guidelines described in the previous section. 38 primary studies (identified through the mentioned electronic databases). In the Fig. 3 the SME is presented.

\section{Study quality assessments}

Each of the studies that remained after stage it was assessed independently by the author, according to criteria of quality; these criteria were informed by those proposed for the Critical Appraisal Skills Programme (CASP) (in particular, those for assessing the quality of qualitative research) [26], and by principles of good practice for conducting empirical research in software engineering [24]. 


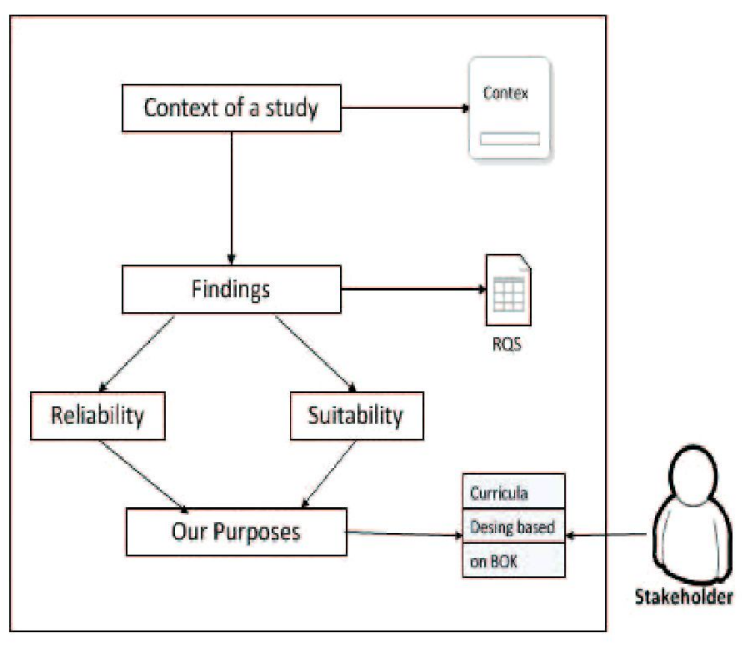

Fig. 3. Systematic Mapping Execution SME

\section{FINDINGS}

BOK is used by individuals for extending their skills and for career development. Researchers may find it useful for identifying technology applicable to their research and to help define the skills required for research teams. The process of building the BOK should assist in highlighting similarities across disciplines, for example, techniques used in materials science that are common between chemistry and physics [8].

Regarding the Knowledge Levels in a BOK, they define the amount of knowledge to be offered within a specific level of an educational program. The greater the level, the more knowledge is offered. RaPSEEM defines the following levels [13].

General Structure Of Bodies Of Knowledge As Base To Desig Curricula:

BOK has a specific structure according the area of engineering or science. In this paper the general structure of BOK in the context of engineering, science, and Software Engineering is described.

Firstly is necessary consider the context of the area of study of BOK in order to establish the core (skills, knowledge, and experience to be taught in the curriculum to achieve the expected student outcomes). In the same way the BOK establishes Knowledge Areas (KAS). Each Knowledge Area descriptions should use the following structure:

- Acronyms.

- Introduction.

- Breakdown of Topics of the KA.

- Matrix of Topics vs. Reference Material.

- List of Further Readings.

- References [2], [3].

Each area is broken down into smaller divisions called units [2], [3], [12], which represent individual thematic modules within an area. Each unit is further subdivided into a set of topics, which are the lowest level of the hierarchy. The topics depend of evolution, and context of KA, and related disciplines [2], [3].

In the context of BOK is necessary a process of update of knowledge in function of the advance of the discipline, and the necessities of the society. In general the BOK has different committees, organization, and groups of collaboration that develop, and update their contexts in function of the advance of the science, and engineering.

In order to formulate a BOK in a bottom-up manner is necessary considering the "materials" from which we can extract knowledge about the targeted discipline. [14].

$\mathrm{BOK}$ is the general name for the three types of resources that the BOK Constructor manages, and it is a term to refer to a novel BOK design principle for new disciplines as well. The resources are materials, descriptions, and the BOK tree, which are linked.

In this paper the general the structure of BOK by levels is showed:

- Firstly, is necessary consider the Core of BOK.

- Secondly KA was establish of BOK. Each area is broken down into smaller divisions called Units, which represent individual thematic modules within an area. Adding a two or three letter suffix to the area identifies each unit. Each unit is further subdivided into a set of topics that is the lowest level of the structure, and the content [2], [3], and [10].

- The integration of news areas, unit, topics depend of the different criteria's that consider the organization and institutions that regularly the different BOK [2], [3], [10].

Software Engineering Body Of Knowledge (SWEBOK).

As software engineering evolved into a stand-alone curriculum a number of technical societies and interested professionals initiated open efforts to better quantify the skills, practices, and processes that form the core body of software engineering knowledge. The two most prominent attempts to codify the elements of software engineering are the Guidelines for Undergraduate Degree Programs in Software Engineering (SE2004), and the SWEBOK [5].

The first step in developing Software Engineering will be to do what has been done for other engineering disciplines identify a Core Body of Knowledge. This process must begin with a description of the tasks that is expecting them to be able to perform [6].

The SWEBOK describes the "sum of knowledge within the profession of software engineering." Since 1993, the IEEE Computer Society and the ACM have been actively promoting software engineering as a profession, notably through their involvement in accreditation activities described before and in the development of a SWEBOK [7].

SWEBOK is also an ISO technical report (ISO/IEC TR 19759:2005) [8]. ISO/IEC 24773:2008 standard [9], which is a framework for comparison of schemes for certifying software 
development professionals, refers to a BOK, for which SWEBOK is a reference IEEE.

Example Of Curricular Proposal Of Knowledge Areas In The Context Of Swebok To Curricular Desig Based In Bok:

In order to respond the RQ2: What would the structure and the kind of contents a Body of Knowledge should be in the context of Software Engineering? Is necessary consider the previous information of the theoretical background of this paper.

In order to apply the previous findings a similar structure, and content of SWEBOK in the versions 2004 [2], and Version 3.0. [3], based in the Bloom taxonomy [11], was proposed.

In order to develop a BOK in the context of Software Engineering was necessary establishing the KAS.

The KAS considers in this proposal considers the table 3 , and 4 .In the same context it was necessary establishing the bounds of each KA.

After the review of the literature and as example of application of structure and contents of BOK in the context of Software Engineering, in this paper two KAS it was proposed: Enterprise Architecture -Innovation and Industrial Viewing.

The establishment of these KAS gave a general vision of the context of our BOK. In the same way it was necessary starting the levels of knowledge our BOK; in this case 3 levels where is detailed a specific domain level. In the same way it was necessary used the correct abbreviation of each $\mathrm{KA}$ in order to identify the context and elements. The uses of correct acronyms permit know, and determine the KA of the BOK.

In the same context it was necessary the development of an introduction of each KA where the characteristics, and constitutive elements were taking account. The descriptions of KA permit that stakeholders have general vision of the context of KA.

In the structure of KA were necessary the establishing of breakdowns of each KA. This division was called Knowledge Units which represent the individual thematic. The modification or increments of the knowledge units of our $\mathrm{BOK}$ depend of modifications of core in consequence of KA. The changes of knowledge units are based on the needs of the discipline in this case the Software Engineering.

Other aspect to consider in the process of development of the $\mathrm{BOK}$ was the matrices of topics in function of referential material of each KA. The referential materials will be information with support scientific, consensual in our case in the context of SWEBOK [2], [3], [9], [10].

The matrix of topics will be broken down into details In order to make the relation with the respective material [2].

On other hand is necessary consider a list the reading to complement the information of our KAS. Specifics topics to include in our proposal of BOK could be.
TABLE II. PROPOSAL OF ADditional KA [37]

\begin{tabular}{|l|l|}
\hline Knowledge Areas: & Units in the context of SE. \\
\hline & Overview of EA. \\
& Structure al Culture of EA. \\
& Values and Risk of creating EA. \\
& Implementation of Methodologies. \\
& Analysis of documentation \\
& frameworks. \\
Enterprise Architecture & Components and Artifacts. \\
(EA)-Innovation & Develop of concurrent and Future \\
& Architecture view in function of the \\
& Innovation. \\
& Develop of EA Management Plan. \\
& Security and Privacy in EA. \\
& Repositories and innovators tools. \\
& Innovation in the context of EA. \\
& Develop of technical, social and \\
& professional skills. \\
& Team work in the industrial context. \\
& Software Line Production. \\
& Estimation and Planning tools. \\
\hline
\end{tabular}

Exist other topics that could be include but this depend the context of application of software engineering. In the same context each unit was subdivided in topic.

In the table 4 some topic of our proposal in the context of curriculum design is proposed.

TABLE III. PROPOSAL OF ADditional TOPICS IN CURRICULUM DESIGN [37]

\begin{tabular}{|c|c|}
\hline \multicolumn{2}{|c|}{ Enterprise Architecture -Innovation(KA) } \\
\hline Units in the context of SE. & TOPICS: \\
\hline Overview of EA. & $\begin{array}{l}\text { Definition of EA. } \\
\text { EA as Meta Discipline. } \\
\text { EA Approach. } \\
\text { EA as Management Program. } \\
\text { Analysis of EA. } \\
\text { Context and application of EA. }\end{array}$ \\
\hline Structure al Culture of EA. & $\begin{array}{l}\text { Influences on the field of EA. } \\
\text { Models of EA. }\end{array}$ \\
\hline $\begin{array}{l}\text { Values and Risk of } \\
\text { creating EA. }\end{array}$ & $\begin{array}{l}\text { Planning EA. } \\
\text { Improved EA. } \\
\text { Managing Risk. } \\
\text { EA Value. } \\
\text { Cost EA. } \\
\text { Linking Strategy, Business and technology } \\
\text { (In the version V.3.0 is consider business } \\
\text { topic in the Area Software Engineering } \\
\text { Economic). }\end{array}$ \\
\hline $\begin{array}{l}\text { Implementation of } \\
\text { Methodologies. }\end{array}$ & Develop of phases of EA. \\
\hline $\begin{array}{l}\text { Analysis of documentation } \\
\text { frameworks. }\end{array}$ & $\begin{array}{l}\text { Origin of frameworks in the context of } \\
\text { EA. } \\
\text { Examples of EA Frameworks. }\end{array}$ \\
\hline Components and Artifacts. & $\begin{array}{l}\text { EA components. } \\
\text { Scenarios EA. } \\
\text { Business: Product and Service. } \\
\text { IT portfolio. }\end{array}$ \\
\hline $\begin{array}{l}\text { Develop of concurrent and } \\
\text { Future Architecture view } \\
\text { in function of the } \\
\text { Innovation. }\end{array}$ & $\begin{array}{l}\text { Levels of EA in Concurrent View. } \\
\text { Levels of EA in Future Views. }\end{array}$ \\
\hline $\begin{array}{l}\text { Develop of EA } \\
\text { Management Plan. }\end{array}$ & $\begin{array}{l}\text { EA Program Management. } \\
\text { ISO to support EA. }\end{array}$ \\
\hline
\end{tabular}




\begin{tabular}{|c|c|}
\hline $\begin{array}{l}\text { Security and Privacy in } \\
\text { EA. }\end{array}$ & $\begin{array}{l}\text { Security Plan. } \\
\text { Privacy in environment EA. }\end{array}$ \\
\hline $\begin{array}{l}\text { Repositories and } \\
\text { innovators tools. }\end{array}$ & $\begin{array}{l}\text { EA Repository. } \\
\text { Business Product. } \\
\text { Infrastructure of Repositories. } \\
\text { Innovation tolls in the context of EA. }\end{array}$ \\
\hline $\begin{array}{l}\text { Innovation in the context } \\
\text { of EA. }\end{array}$ & $\begin{array}{l}\text { Principles of Innovation. } \\
\text { Models of innovation. } \\
\text { Innovation in the context EA. }\end{array}$ \\
\hline \multicolumn{2}{|l|}{ Industrial Viewing.(KA) } \\
\hline $\begin{array}{l}\text { Develop of technical, } \\
\text { social and professional } \\
\text { skills. }\end{array}$ & \\
\hline $\begin{array}{l}\text { Team work in the } \\
\text { industrial context }\end{array}$ & $\begin{array}{l}\text { The organizational context for } \\
\text { Teamwork. }\end{array}$ \\
\hline Software Line Production & $\begin{array}{l}\text { Software Reuse. } \\
\text { Software components. } \\
\text { Software factory. }\end{array}$ \\
\hline $\begin{array}{l}\text { Estimation and Planning } \\
\text { tools }\end{array}$ & $\begin{array}{l}\text { Estimation and innovation in software } \\
\text { products. } \\
\text { Use of tools in the industry of software. }\end{array}$ \\
\hline
\end{tabular}

Each topic will be subdivided in subtopics in order to deepen the knowledge. The addition of KA, unit, topics, and subtopics was justified according the evolution of engineering and science [2], [3], [9], [10]. Since the required core competencies and skill sets for almost any profession evolves and changes over the years, its BOK has to be dynamic, in order to incorporate new information, and techniques, and maintain the relevance of the curriculum.

In addition to extending the conception of the SWEBOK 2004 [2], to include new kinds of knowledge a different approach will also have to take to its organization and the way it access.

In other hand we need consider some criteria's to propose a news KAS such as:

- Context of the KA.

- Content of KA.

- Relation between the new KA, and the related disciplines.

- Establish the breakdown of KA.

- Coherence of the units, topics with the goal, and application of the new KA.

- Online, and consensual information to support the KA.

- Identify, and link concepts involved in Software Engineering with the real context. [2], [3], [9], [10].

Relevance Of Body Of Knowledge In The Context Of Software Engineering:

Software organizations that want to assess the knowledge of their engineers could use this SWEBOK in designing a competency evaluation system. Such a competency system could use this SWEBOK 2004 [2], to help identify and judge what kind of software engineering knowledge is required to accomplish the tasks associated with individual softwarerelated roles. Such an assessment might be coupled with the use of this SWEBOK 2004 [2] to design training programs and to develop an overall effort to improve an organization's software processes [8].

In [2], provides the means for studying and addressing a number of issues related to the software engineering profession.

First, a body of knowledge could be used to define the profession itself or, at least, to delineate the knowledge associated with the profession. Such a definition is essential to the maturation of a discipline and is a necessary step in determining the professional standards, and procedures required for the effective practice of software engineering.

The definition and the professional standards could then be used to develop criteria, and assessment instruments for the certification and licensing of software engineers. In addition, [2], could be used by individual engineers to assess their own Knowledge about the software engineering profession, and to provide a framework that they can use to plan their professional development.

Software plays a critical role in industry, academia, and everyday life. Owing to the fact that practices in other fields such as science, engineering and business have changed over the years [15].

\section{Conclusion}

- In order to consider the area of engineering as discipline is necessary know the principles, and frameworks of their BOK.

- The design of curriculum based in BOK in the context of engineering is important to respond the training needs of future professional to they acquire the competencies in the social, business, educational, and industrial.

- BOK provides the basis for curriculum development, maintenance, and supports professional development and any current and future certification schemes.

- A general structure of BOK in the engineering it was established. This structure begins with the set of Knowledge Areas, continue with Units, and end with Topics according to the research area.

- Other aspect to consider in the developing of BOK is the degree of maturity of the discipline, skills, and competences.

- In the context of software engineering SWEBOK was analyzed; this permitted know the structure, and taxonomies used in this guide. SWEBOK has a hierarchical structure ordered by Knowledge Areas, Knowledge Units, and Knowledge Topics. The taxonomies used in SWEBOK were Bloom, and Vincenti.

- In the version SWEBOK 2004 it was considered 10 Knowledge Area (KA) in contrast the version 3.0 (2014) where $15 \mathrm{KA}$ were proposed. In addition in this paper thesis as example of application of structure and content of Bok in the context of Software Engineering 
it was proposed 2 additional Knowledge Area: Enterprise Architecture-Innovation and Industrial Viewing because in the educational, technological and industrial context are necessary. Established the additional two Knowledge Areas it was proposed the units of each area. The units proposed had a relation with the advances in the context of software engineering. After of established the units in this paper were necessary consider the topics of each unit.

\section{ACKNOWLEDGMENT}

The authors express their gratitude to the Waseda University, Technical University of Madrid (UPM), in particular to the Doctoral Program of Science and Technology of Computing for Smart Cites, The Department of Information Systems UPM CITSEM, and PhD. Santiago Acosta Aide Vice-Chancellor of the Technical University of Loja for their constantly support.

\section{REFERENCES}

[1] J. Gamaliel, J. Fernandez, and A. Serrano, "Competency Framework for Software Engineers", IEEE, DOI 10.1109/CSEET.2010.21, Mexico, Tijuana, 2010.

[2] A. Alain., J. Moore, P. Bourque, R. Dupuis, and L. Tripp, "Guide to the Software Engineering Body of Knowledge"- 2004 Version - SWEBOK, IEEE-Computer Society, 2004.

[3] P. Bourque, and R. Dupuis.,"Swebok Version 3.0", IEEE, ISBN-10: 07695-5166-1, 2014.

[4] M. Shaw, J. Herbsleb, I. Ozkaya, and D. Root, 2006, "Deciding What to Design: Closing a Gap in Software Engineering Education", SpringerVerlag Berlin Heidelberg, 2006.

[5] H. Welt, "Teaching a Service Course in Software Engineering", IEEE 37th ASEE/IEEE Frontiers in Education Conference, 2007.

[6] P. Lorge, "Software Engineering Programs Are Not Computer Science Programs", IEEE, 1999.

[7] P. Bourque, J. More, and Tripp, "The Guide to Software Engineering Body of Knowledge", IEEE, 1999.

[8] ISO/IEC TR 19759:2005 Software Engineering, "Guide to the Software Engineering Body of Knowledge. International Organization for Standardization", IEEE, Geneva, 2005.

[9] ISO/IEC 24773:2008 Software Engineering, "Certification of Software Engineering Professionals - Comparison Framework", International Organization for Standardization, IEEE, Geneva, 2008.

[10] B. Thomas, I. Hirmanpour, S. Khajenoori, R. Turner, and A. Qasem," $A$ Software Engineering Body of Knowledge Version 1.0", Carnegie Mellon - Software Engineering Institute, 1999.

[11] B. Bloom, "Taxonomy of Educational Objectives: The Classification of Educational Goals," Mackay, IEEE, 1959.

[12] ISO/IEC 12207, "Information Technology - Software Life Cycle", IEEE, 1995

[13] M. Katko, "A Method for Designing Software Engineering Educational Programs", IEEE, 2012.

[14] Y. Misusage, Y. Shoji. And K. Ito, "A Wiki-based Collective Intelligence Approach to Formulate a Body of Knowledge (Bok) for a New Discipline", ACM, 2010.

[15] M. Raza., "Imparting Effective Software Engineering Education", ACM SIGSOFT Software Engineering Notes, 2006.

[16] B. Kitchenham, D., Budgen, and B. Pearl, "Using mapping studies as the basis for further research-a participant-observer case study. Information and Software Technology", 53(6), 638-651, Science Direct, 2011.

[17] B. Kitchenham, and S.Charters, "Guidelines for performing Systematic
Literature Reviews in Software Engineering", Technical Report, EBSE, IEEE, 2007.

[18] R. S. M. Petersen, K. Feldt, and M. Mattsson, "Systematic mapping studies in software engineering" In EASE'08, pages 1-10, Bari, Italy, 2008.

[19] C. Fernandez, M., Daneva, K. Sikkel, R. Wieringa, O., Dieste, and O. Pastor. "A systematic mapping study on empirical evaluation of software requirements specifications techniques", ESEM 3rd International Symposium, 502-505, 2009.

[20] M. Mannan, and M. Usan," Software Engineering Curriculum: "A Systematic Mapping Study", IEEE, 2011.

[21] P. Brereton, B, Kitchenham, D., Budgen, and M.Turner,"Lessons from applying the systematic literature review process within the software engineering domain." JSS 80, pp. 571-583, 2011.

[22] B. Kitchenham, S. Pfleeger, L. Pickard, P. Jones., K. Hoaglin and J. Rosenberg., "Preliminary guidelines for empirical research in software engineering". IEEE, Transactions on Software Engineering, 2002.

[23] D. Budgen, M., Turner, P., Brereton, and B. Kitchenham," Using mapping studies in software engineering, in: Proceedings of PPIG 2008', Lancaster University, pp. 195-204, 2008.

[24] B.Kitchenham, and S Pfleeger. "Principles of survey research": Part 2 6. ACM SIGSOFT Software Engineering Notes, 2002.

[25] D. Cruzes and D. Tore," Research synthesis in software engineering: $A$ tertiary study. Inf. Softw. Technol", 53(5): 440455, 2011.

[26] V. Braun, and V. Clarke, "Using thematic analysis in psychology, Qualitative Research in Psychology", 3(2):77-101. Routledge, IEEE, 2006.

[27] M. Staples, and M. Niazi, "Systematic review: Systematic review of organizational motivations for adopting CMM-based SPI," Inf. Softw. Technol. 50 (7-8): 605-620, 2008.

[28] T. Greenhalgh, "How to Read a Paper", Second ed., BMJ Publishing Group, London, 2011.

[29] A. Fink, "Conducting Research Literature Reviews". From the Internet to Paper, Sage Publication, Inc, 2005.

[30] J. Floersch, J. Longhofer, L, Kranke, D., and Townsend, L., "Integrating Thematic, Grounded Theory and Narrative Analysis: A Case Study of Adolescent Psychotropic Treatment", Qualitative Social Work 9: 407$425,2010$.

[31] B. Dunne, E. Blauch, J. Andrew, H., Ferguson, R., Sterian, A. Wolffe, "Work In Progress - CE Curriculum Development Based on IEEECS/ACM Body of Knowledge Recommendations", IEEE, DOI 10.1109/FIE.2007.4417911, Milwaukee, WI,2007.

[32] E. Sinderson, and L. Spirkovska, "Undergraduate software engineering education: the body of knowledge, existing programs and accreditation", IEEE, DOI, 10.1109/CSEE.2001.913847, Charlotte, NC, 2001.

[33] J. Kontio, J. Ahokas, M. Poyry, W. Päivi, J. Makela, M. Tyrvainen, "Software Business Education for Software Engineers: Towards an Integrated Curriculum". IEEE, DOI 10.1109/CSEETW.2006.15, 2006.

[34] K., Mattsson, "A Method for Designing Software Engineering Educational Programs", IEEE. DOI 10.1109/CSEET.2012.34, Nanjing, Jiangsu, 2012

[35] C. Timothy, R. Leblanc, J. Richard, K. Sobel, E. Ann, T. Hilburn, B. Thomas, "SE2004: Recommendations for Undergraduate Software Engineering Curricula", IEEE, DOI 10.1109/MS.2006.171,2006.

[36] F. Chen, "The instructional models and guidelines for developing a curriculum in eco-design", IEEE, DOI 10.1109/.2001.992436, 2001.

[37] P. Quezada, "Structure, Contents and Importance of Bodies of Knowledge in field Engineering, Science and SWEBOK", Master Thesis, Technical University of Madrid UPM, 2014.

[38] B. Penzenstadler, D. Mendez Fernandez, D. Richardson, D. Callele, and $\mathrm{K}$. Wnuk, The requirements engineering body of knowledge (rebok)," in Requirements Engineering Conference (RE), 2013 21st IEEE International, July 2013, pp. 377-379. 